\title{
Chemically-Induced Peptic Ulcer: Gastroprotective Effects of Peach Fruit
}

\author{
Qaiser Jabeen*, Sidra Arif and Fayyaz Anjum \\ Department of Pharmacy, Faculty of Pharmacy and Alternative Medicine, The Islamia University of Bahawalpur, Pakistan
}

Received: 制 June 12, 2018; Published: 阱June 18, 2018

*Corresponding author: Qaiser Jabeen, Department of Pharmacy, Faculty of Pharmacy and Alternative Medicine, The Islamia University of Bahawalpur, Pakistan

\begin{abstract}
Background: Peptic ulcer, an inflammatory breach in the gastric and duodenal mucosa, is caused by hyper secretion of gastric acid and defective mucosal protective elements, affecting approximately 4 million people each year. The currently available antiulcer drugs are reported to have severe side effects. Hence, there is a need to develop more effective and less toxic alternative therapeutic agents from natural sources. The current study was conducted to investigate the therapeutic potential of Prunus persica Linn. Batsch fruit (Peach) against chemically-induced gastric and duodenal ulcers.
\end{abstract}

Material and Methodology: 70\% aqueous methanolic crude extract of Prunus persica (Pp.Cr) was prepared. Gastroprotective effects were evaluated by oral administration of Pp.Cr at the doses of 100,300,500 mg/kg for ten days. Normal control and intoxicated groups were treated with distilled water. Bismuth subsalicylate $(88 \mathrm{mg} / \mathrm{kg})$ was administered to the standard control group. On 10 th day, all animals were intoxicated with ethanol ( $5 \mathrm{ml} / \mathrm{kg}$ ) except normal control group, and one hour after intoxication, all animals were sacrificed, stomach isolated; and pH and acidity of gastric contents, ulcer index and percentage protection were calculated. One stomach from each group was analyzed histo pathologically. Duodenal protective effects were assessed by administering Pp.Cr (100, $300,500 \mathrm{mg} / \mathrm{kg}$ ) for fourteen days. The standard control group was treated with cimetidine (100 mg/kg). On 14th day, cysteamine $(600 \mathrm{mg} / \mathrm{kg})$ was administered in two divided doses at an interval of four hours to experimental animals to induce duodenal ulcer. All animals were dissected out 48 hours after the administration of first dose of cysteamine. Duodenum was isolated and analyzed for severity score. Histopathological examination of one duodenum from each group was performed.

Results: In gastric ulcer model, Pp.Cr was found to increase pH and decrease the total acidity of gastric contents, and decrease the ulcer index, in dose-dependent manner at the doses of 100, 300 and $500 \mathrm{mg} / \mathrm{kg}$. In duodenal ulcer model, Pp.Cr was observed to decrease the severity score and ulcer index, again in dose-dependent manner.

Conclusion: The results of current study demonstrate the gastric and duodenal protective effects of the crude extract of Prunus persica (Pp.Cr), corroborating their folkloric use in the prevention and treatment of peptic ulcer.

Keywords: Ulcer; Duodenum; Prunus Persica; Gastroprotective; Gastric Ph; Ulcer Index

\section{Introduction}

Peptic ulcer, an inflammatory breach in the lining of GIT, results from hyper secretion of gastric acid or defects in mucosal protective factors [1]. The most frequent sites of ulcer formation are stomach and proximal portion of duodenum and the ratio of duodenal to gastric ulcers is 4:1 [2]. Peptic ulcer is caused by various noxious factors; such as Helicobacter pylori infection, NSAIDs, alcohol intake, smoking and stress. $60 \%$ of gastric and up to $90 \%$ of duodenal ulcers develop due to the $H$. pylori infection
[3]. Peptic ulcer can be treated through different approaches, based on chemically synthesized drugs; i.e. reduction of gastric acid secretion (proton pump inhibitors, $\mathrm{H}_{2}$ receptors antagonists, anticholinergics, prostaglandin analogues), neutralization of gastric acid secretion (antacids), protection of GIT mucosa (sucralfate, bismuth subsalicylate) and use of antimicrobial drugs like amoxicillin, clarithromycin, tetracycline and metronidazole [4]. No doubt, the available drugs have reduced the incidence 
and prevalence of peptic ulcer but they are associated with severe side effects; such as impotence, arrhythmias, hyperplasia, gynaecomastia, and hematopoietic changes [5]. Therefore, there is a constant need to explore the new possible therapies with lesser side effects to reduce or treat the peptic ulcer problems and plants are the best alternatives which are being used from the ancient times. World Health Organization (WHO) has estimated that about $75 \%$ of the world's population rely on herbal medicines for the prevention and treatment of various diseases because of their fewer side effects and low cost. Approx. $80 \%$ of population in Pakistan is using indigenous plants for the treatment of various diseases [6]. Prunus persica used in the present study is a tree or large shrub having tremendous medicinal importance.

Different parts of plant; i.e. leaves, flowers, fruits, kernels of fruit and seeds have traditional medicinal uses and extensively studied. The plant is used for the treatment of whooping cough, chronic bronchitis and gastritis. The plant has demulcent, antiscorbutic, aphrodisiac, anti-pyretic and anthelmintic activities. Leaves have demulcent, expectorant, vermicidal, anthelmintic, insecticidal, sedative and diuretic properties. Leaf paste is used externally to kill worms in wounds and fungal infections. The flowers are used as laxative and diuretic, oil extracted from seeds, is used for the treatment of piles, stomach troubles of children and earache and used as an abortifacient. Peach kernels are used for the treatment of menstrual disorders, blood disorders, coughs and rheumatism. The bark is used to treat the leprosy and jaundice [7]. Prunus persica has been reported to possess Antiallergic [8], Antibacterial [9], Anti-inflammatory [10], Antiphotoaging [11], Prokinetic [12] and Antioxidant properties [13]. Hence, indigenous medicinal plant; Prunus persica, was selected on the basis of its traditional use as antiulcer agent. The objective of the current study was to investigate the antiulcerogenic potential of the crude extract of Prunus persica fruit by using chemically-induced peptic ulcer models; i.e. ethanol induced-gastric ulceration and cysteamineinduced duodenal ulceration.

\section{Research Methodology}

\section{Material and Equipment}

All chemicals used in experiments were of analytical grade including; Bismuth subsalicylate, Cimetidine, Cysteamine hydrochloride, Ethanol, Formalin, Ketamine and Xylazine. Equipment used were centrifuge machine, digital weighing balance, oven, $\mathrm{pH}$ meter, refrigerator, rotary evaporator and vortex mixer.

\section{Phytochemical Section}

Collection of Plant Material: The frsesh fruit of Prunus persica (Peach) was purchased from local market of Bahawalpur, Pakistan. After collection, plant was identified by authentic botanist; $\mathrm{Mr}$. Abdul Hamid, department of Life Sciences, the Islamia University of Bahawalpur, Pakistan. Dried plant specimen was deposited in Herbarium of Pharmacology research laboratory, department of Pharmacy and Alternative Medicine, the Islamia University of Bahawalpur, Pakistan. Voucher number PP-FT-05-15-92 was issued for future reference.

Preparation of the Crude Extract: After removal of seeds, fresh fruit of Prunus persica was cut into small pieces and soaked in $70 \%$ aqueous methanol for three days with occasional shaking at room temperature. Then the soaked material was filtered first through muslin cloth and then through filter paper. The process of soaking and filtration was repeated twice. After third filtration, residue was discarded. Filtrate was subjected to evaporation using rotary evaporator to remove solvent under reduced temperature $\left(50^{\circ} \mathrm{C}\right)$ and pressure. The obtained crude extract was then labelled as Pp.Cr and weighed to calculate percentage yield. The extract was stored in freezer for future use.

Phytochemical Analysis of Pp.Cr: The crude extract of Prunus persica (Pp.Cr) was subjected to phytochemical analysis for the detection of secondary metabolites; i.e. alkaloids, carbohydrates, coumarins, flavonoids, glycosides, phenols, phlobatannins, proteins, quinones, saponins, tannins and terpenes.

\section{Pharmacological Section}

Experimental Animals: Wistar albino rats (150-250 g) and Swiss albino mice (18-30 g) of either sex were housed in animal house of Pharmacology Research Laboratory, department of Pharmacy, faculty of Pharmacy and Alternative Medicine, the Islamia University of Bahawalpur. Animals were kept in polycarbonate cages $\left(47 \times 34 \times 18 \mathrm{~cm}^{3}\right)$ under standard conditions of temperature $\left(25 \pm 2^{\circ} \mathrm{C}\right)$, humidity $(60 \pm 5 \%)$ and $12 \mathrm{~h} / 12 \mathrm{~h}$ light and dark cycle. Animals were provided with standard pellet diet and tap water ad libitum and allowed to acclimatize for at least one week before the commencement of experiment. The study protocols and procedures were approved by the Institutional Research Ethics Committee of department of Pharmacy and Alternative Medicine, Islamia University of Bahawalpur; i.e. Pharmacy Research Ethics Committee (PREC) and the reference No. 40-2015/PREC; dated 02.09.2015 was issued for future reference.

Experimental Models: Peptic ulcer was induced by intragastric administration of ethanol (gastric ulcer) and cysteamine hydrochloride (duodenal ulcer) to evaluate the antiulcer potential of Pp.Cr.

a) Ethanol-Induced Gastric Ulcer: Gastric ulcer was induced by oral administration of ethanol $(5 \mathrm{ml} / \mathrm{kg})$ in wistar albino rats, according to the method described by Ahmed [14]. Animals were divided into six groups, each comprises of six animals. Normal control group and intoxicated groups were treated with distilled water $(5 \mathrm{ml} / \mathrm{kg}$, p.o) for 10 days. Treatment groups received different doses $(100,300$ and $500 \mathrm{mg} / \mathrm{kg})$ of Pp.Cr and the standard control group was treated with bismuth subsalicylate $(88 \mathrm{mg} /$ $\mathrm{kg}$ ) for 10 days. On 10th day, one hour after respective treatment to 24 hour fasted rats, ethanol $(5 \mathrm{ml} / \mathrm{kg}$ ) was administered orally 
to all the animals except the normal control group. One hour after administration of ethanol, all animals were anaesthetized with ketamine $(50 \mathrm{mg} / \mathrm{kg}) /$ Xylazine $(5 \mathrm{mg} / \mathrm{kg})$ combination and sacrificed. The stomach was isolated from each animal and gastric contents were collected in centrifuge tubes.

\section{i) Analysis of Gastric Contents for Ph and Total Acidity}

Gastric contents were centrifuged at $1000 \mathrm{rpm}$ for 10 minutes. $\mathrm{pH}$ of supernatant was noted using $\mathrm{pH}$ meter. $1 \mathrm{ml}$ of supernatant liquid was taken in conical flask and diluted with distilled water to make the volume up to $10 \mathrm{ml}$. Two or three drops of phenolphthalein were added in this solution and titrated with $0.01 \mathrm{~N} \mathrm{NaOH}$ until the appearance of pink colour. The volume of $0.01 \mathrm{~N} \mathrm{NaOH}$ used corresponds to total acidity which is expressed as $\mathrm{mEq} / \mathrm{L} / 100 \mathrm{~g}$ of gastric contents. Total acidity was calculated using following formula: Acidity $(\mathrm{meq} / \mathrm{L} / 100 \mathrm{~g})=($ Vol. of $\mathrm{NaOH} \times$ Normality $\times$ 100) $/ 0.1$

\section{ii) Scoring of Ulcer}

After isolation, stomach was rinsed with normal saline. Each stomach was cut open along the greater curvature and observed for ulcerative lesions. Any bulging or inflammation in the stomach is the indicator of ulcer. The number of ulcers per animal was counted and ulcer scoring was done according to severity of ulcer with the help of magnifying glass [15].

$0=$ No ulcers

1 = Changes on superficial layer of the mucosa without congestion

$2=$ Necrotic changes on half the mucosal thickness

$3=$ Necrotic changes on more than $2 / 3$ rd of the mucosal thickness

$4=$ Complete mucosal destruction with hemorrhage

iii) Determination of Ulcer Index and \% Protection

The Ulcer Index (UI) was calculated using following formula:

$\mathrm{UI}=\mathrm{Un}+\mathrm{Us}+\mathrm{Up} \times 10-1$

Un = average number of ulcers per animal

Us = average severity score

$\mathrm{Up}=$ percentage of animals with ulcers

$\%$ Protection was calculated using following formula:

$\%$ Protection $=$ UI Intoxicated-UI treated/UI Intoxicated $\times 100$ [16].

b) Cysteamine-Induced Duodenal Ulcer: Duodenal ulcer was induced by oral administration of cysteamine hydrochloride $(600 \mathrm{mg} / \mathrm{kg})$ in two divided doses at an interval of 4 hours in wistar albino rats, according to the method described by Santos with slight modifications [17]. Animals were divided into six group, each comprising of six animals. Normal control and intoxicated groups were treated with distilled water $(5 \mathrm{ml} / \mathrm{kg})$ for 14 days. Treatment groups received different doses (100, 300 and 500mg/kg) of Pp.Cr, the standard control group was treated with cimetidine $(100 \mathrm{mg} /$ $\mathrm{kg}$ ) for 14 days. On 14th day, one hour after respective treatment, cysteamine hydrochloride $(600 \mathrm{mg} / \mathrm{kg}$ ) was administered orally in two doses at an interval of 4 hours to all animals except the normal control group. Twenty four hours fasted animals were dissected out 48 hours after the first dose of cysteamine hydrochloride. Duodenum from each animal was isolated and analyzed for severity score.

i) Scoring of Ulcer: Duodenum from each animal was cut open along the antimesenteric side and washed with normal saline. Ulcer scoring was done according to severity of ulcer with the help of magnifying glass.

$0=$ No ulcer

1 = Superficial lesions on duodenal mucosa

2 = Deep ulcer or transmural ulcer

$3=$ Perforated or penetrated ulcer

ii) Determination of Ulcer Index and \% Protection: The Ulcer Index (UI) was calculated using following formula:

$\mathrm{UI}=$ Average of severity score + (ratio of ulcer positive/total animal in each group $\times 2$ )

$\%$ Protection was calculated using following formula:

$\%$ Protection $=$ UI intoxicated-UI treated $/$ UI intoxicated $\times 100$ [18]

\section{c) Histopathological Examination}

The isolated stomach and duodenum were preserved in $10 \%$ formalin. Tissues were sectioned at $5 \mu \mathrm{m}$, stained with Haematoxylin and Eosin and analyzed under light microscope to observe histopathological changes; e.g. oedema, inflammation, infiltration and erosion in stomach and duodenum [13].

\section{d) Acute Toxicity Test}

Acute toxicity assay was performed according to the guidelines of OECD (Organization of Economic Co-operation and Development). Swiss albino mice weighing 18-30g were divided into 5 groups each consisting of 5 animals. Mice were fasted overnight before the study, however food was provided to the animals during the study. Normal control group received distilled water $(10 \mathrm{ml} / \mathrm{kg})$ orally whereas treatment groups received different doses; i.e. 500, 1000, 5000 and $10,000 \mathrm{mg} / \mathrm{kg}$ of Pp.Cr. Following parameters were observed: alertness, grooming, writhing reflex, corneal reflex, convulsions, lacrimation, salivation, urination, sweating, hyperactivity, touch response, pain response, gripping strength and righting reflex at $0.5,1,2,4,6,12,24,48,72$ hours, 7 and 14th day and mortality, if any, was noted after 48 hours [19]. 


\section{Statistical Analysis}

The interpretation of the results was done by expressing the data as Mean + SEM. Results of treatment groups were compared with intoxicated group using one way Analysis of Variance (ANOVA). All the data was analyzed using Graph Pad Prism software version 5 . The results were considered to be significant at $\mathrm{p}<0.05$ level.

\section{Results}

\section{Phytochemical Analysis}

Medicinal plants are backbone of traditional system of medicine and are enriched in phytochemical constituents which serve as lead compounds in drug discovery and design. In the current study, 70\% aqueous methanolic extract of Prunus persica (Pp.Cr) was prepared and phytochemical analysis was performed that confirms the presence of alkaloids, carbohydrates, flavonoids, glycosides, phenols, proteins, tannins and terpenes.

\section{Pharmacological Section}

\section{Acute Toxicity Studies}

It was observed that the $70 \%$ methanolic crude extract of the plant P. persica was safe up to the dose of $10 \mathrm{~g} / \mathrm{kg}$.

\section{Gastroprotective Effects of Pp.Cr against Ethanol-Induced Gastric Ulceration}

\section{a) Effects of Pp.Cr on Ph of Gastric Contents}

It was observed that Intoxicated group showed highly significant $(\mathrm{p}<0.001)$ reduction in $\mathrm{pH}$ of gastric contents as compared to normal control group. The $\mathrm{pH}$ of gastric contents in bismuth subsalicylate treated group was highest which was statistically highly significant $(p<0.001)$ when compared with the intoxicated group. Pretreatment with 100, 300 and $500 \mathrm{mg} /$ $\mathrm{kg}$ of Pp.Cr produced highly significant $(\mathrm{p}<0.001)$ increase in $\mathrm{pH}$ dose dependently (as shown in Figure 1A) in comparison with intoxicated group. The effects of Pp.Cr are summarized in Table 1.
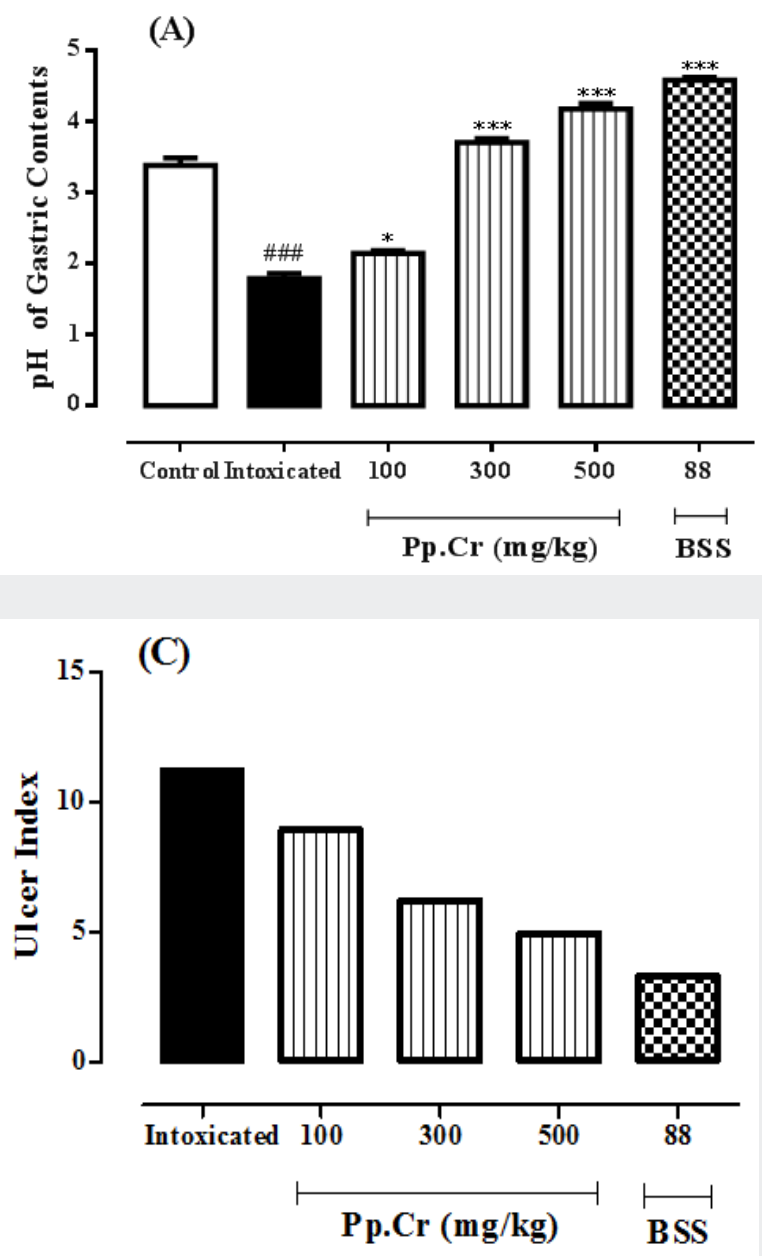
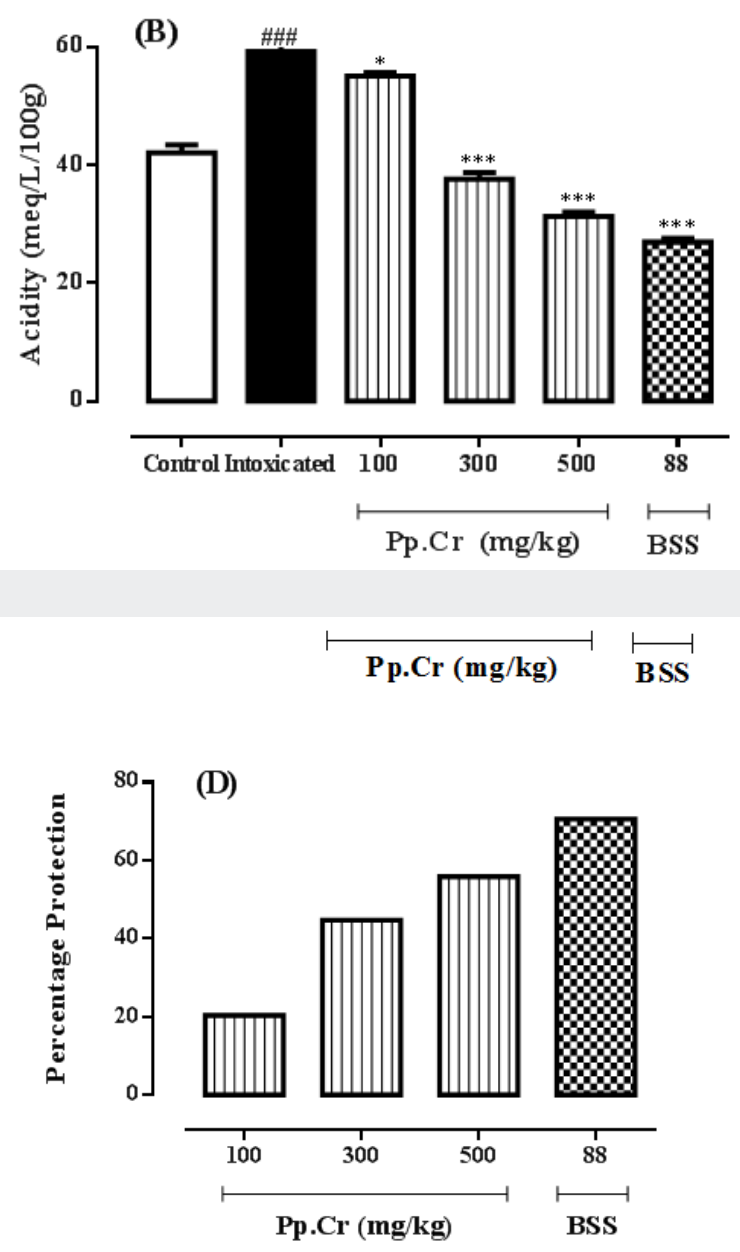

Figure 1: The graphs showing the effects of the crude extract of Prunus persica (Pp.Cr) alongwith bismuth subsalicylate (BSS), on (A) pH of gastric contents, (B) Acidity, (C) Ulcer index and (D) percent gastric protection in ethanol-induced gastric ulceration in rats. 
Table 1: The effects of the crude extract of Prunus persica (Pp.Cr) alongwith bismuth subsalicylate, on $\mathrm{pH}$, total acidity of gastric contents, ulcer index and \% protection in ethanol-induced gastric ulceration in rats.

\begin{tabular}{|c|c|c|c|c|}
\hline Treatment & pH of Gastric Content & Total Acidity (meq/L/100g) & Ulcer & \%Protection \\
\hline Control Group (Distilled water, 5 ml/kg) & $3.38 \pm 0.1$ & $42.17 \pm 1.27$ & 11.21 & - \\
\hline Intoxicated Group (D.W + Intoxication) & $1.79 \pm 0.06 \# \# \#$ & $59.33 \pm 0.84 \# \# \#$ & 8.93 & 20.33 \\
\hline Pp.Cr (100 mg/kg + intoxication) & $2.14 \pm 0.04^{*}$ & $55.17 \pm 0.6^{*}$ & 6.20 & 44.69 \\
\hline Pp.Cr (300 mg/kg + intoxication) & $3.7 \pm 0.05^{* * *}$ & $37.67 \pm 1.14^{* * *}$ & 4.95 & 55.84 \\
\hline Pp.Cr (500 mg/kg + intoxication) & $4.17 \pm 0.06^{* * *}$ & $31.33 \pm 0.76^{* * *}$ & 3.30 & 70.56 \\
\hline $\begin{array}{c}\text { Standard (Bismuth subsalicylate+ } \\
\text { intoxication) }\end{array}$ & $4.58 \pm 0.03^{* * *}$ & $27 \pm 0.57^{* * *}$ & \\
\hline
\end{tabular}

The values are expressed as mean \pm SEM of six animals in each group and the results are analyzed using one way ANOVA. The values of treated groups are compared with those of intoxicated group. P values are considered as significant $\left(^{*}\right)$ if $p<0.05$ and highly significant $\left(^{* * *}\right)$ if $p<0.001$. The values of intoxicated group are also compared with normal control group and considered highly significant (\#\#) if $\mathrm{p}<0.001$.

\section{b) Effects Pp.Cr on Total Acidity of Gastric Contents}

Oral administration of the crude extract of Prunus persica (Pp. $\mathrm{Cr}$ ), at the doses of 100,300 and $500 \mathrm{mg} / \mathrm{kg}$, as well as bismuth subsalicylate $(88 \mathrm{mg} / \mathrm{kg})$ for ten days showed the dose-dependent reduction in total acidity of gastric contents (Table 1). The rise in total acidity in intoxicated group was highly significant $(\mathrm{p}<0.001)$ as compared to normal control group. BSS treated group exhibited significant $(\mathrm{p}<0.001)$ reduction in total acidity as compared to the intoxicated group. Pp.Cr $100 \mathrm{mg} / \mathrm{kg}$ significantly $(\mathrm{p}<0.05)$ reduced the total acidity when compared with intoxicated group. The total acidity values for Pp.Cr treated groups at the doses of $300 \mathrm{mg} / \mathrm{kg}$ and $500 \mathrm{mg} / \mathrm{kg}$ showed highly significant reduction in total acidity as compared to intoxicated group; i.e. $\mathrm{P}<0.001$ as depicted in Figure 1B. The results Pp.Cr (500 mg/kg) were comparable with BSS treated group.

\section{e) Effects of Pp.Cr on Histopathological Parameters}

\section{c) Effects of Pp.Cr on Ulcer Index}

The crude extract of Prunus persica (Pp.Cr) was observed to decrease the ulcer index in dose- dependent fashion as summarized in Table 1. The value of ulcer index in intoxicated group was 11.21 while it was 3.3 in BSS treated group. The values of ulcer indices in Pp.Cr treated groups were found to be; 8.93, 6.20 and 4.95 at the doses of 100,300 and $500 \mathrm{mg} / \mathrm{kg}$ respectively. The results are elaborated in Figure 1C.

\section{d) Effects of Pp.Cr on Gastric Percent Protection}

The percentage protection shown by Pp.Cr after 10 days of the administration was $20.33 \%, 44.69 \%$, and $55.84 \%$ at the doses of 100,300 and $500 \mathrm{mg} / \mathrm{kg}$ as shown in Table 1 . The gastric percent protection at different doses of $\mathrm{Pp} . \mathrm{Cr}$ that is dose-dependent (Figure 1D). The standard control group showed the highest gastroprotective effects; i.e. $70.56 \%$.

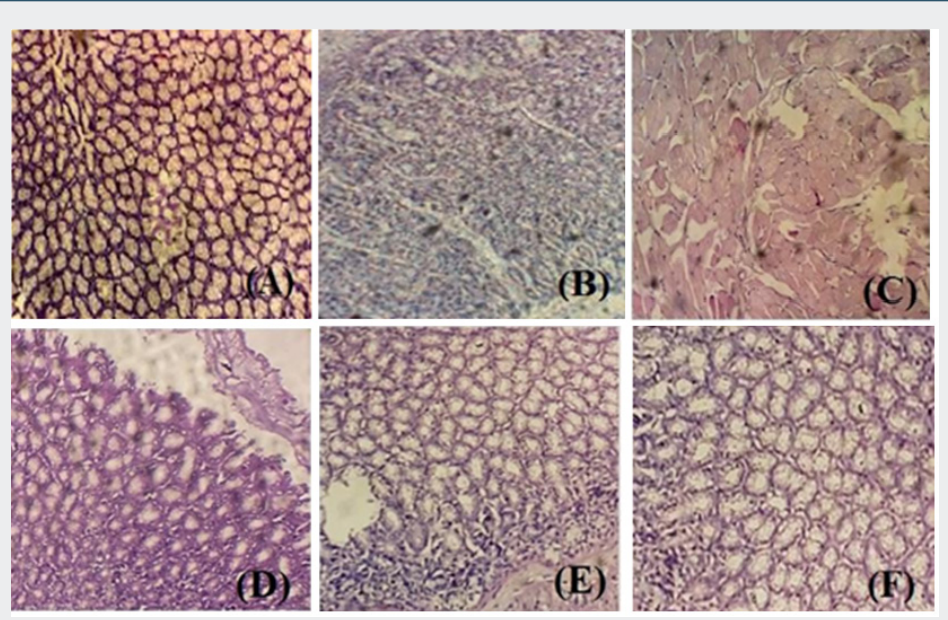

Figure 2: The effects of different doses of Pp.Cr and bismuth subsalicylate on ethanol-induced histopathogical alterations (A) normal control, (B) intoxicated (ethanol $5 \mathrm{ml} / \mathrm{kg}$ ), (C) Pp.Cr $100 \mathrm{mg} / \mathrm{kg}+$ intoxication, (D) Pp.Cr $300 \mathrm{mg} / \mathrm{kg}+$ intoxication, (E) Pp.Cr $500 \mathrm{mg} / \mathrm{kg}$ + intoxication and (F) BSS $88 \mathrm{mg} / \mathrm{kg}+$ intoxication 
Histopathological examination of stomach from one animal of each group was performed to confirm the ulcer formation and to evaluate the gastroptrotective effects of different doses of Pp.Cr. No gastric mucosal damage was observed in normal control group (Figure 2A). Intoxicated group showed the typical characteristics of ethanol-induced ulcer; i.e. gastric mucosal damage, edema and leucocytes infiltration of the mucosal layer (Figure 2B). Histological examination indicated that pretreatment with different doses 100, 300 and $500 \mathrm{mg} / \mathrm{kg}$ (Figures 2C-2E) of Pp.Cr and bismuth subsalicylate $(88 \mathrm{mg} / \mathrm{kg}$, Figure $2 \mathrm{~F}$ ) showed the gastroprotective effects as evidenced by reduction in mucosal damage and edema. Pp.Cr was found to prevent the mucosal damage significantly.

\section{Protective Effects of Pp.Cr against Cysteamine-Induced Duodenal Ulceration}

\section{Effects of Pp.Cr on Severity Score of Duodenal Ulcer}

Table 2: The effects of the crude extract of Prunus persica (Pp.Cr) along with cimetidine on severity score, ulcer index and duodenal percent protection in cysteamine-induced duodenal ulceration in rats.

\begin{tabular}{|c|c|c|c|}
\hline Treatment & Severity Score & Ulcer Index & \%Protection \\
\hline Intoxicated Group (Distilled water + Intoxication) & $2.50 \pm 0.22 \# \# \#$ & 4.5 & - \\
\hline Pp.Cr (100 mg/kg + intoxication) & $1.83 \pm 0.16$ & 3.83 & 26.00 \\
\hline Pp.Cr (300 mg/kg + intoxication) & $1.33 \pm 0.33^{*}$ & 2.99 & 37.33 \\
\hline Pp.Cr (500 mg/kg + intoxication) & $0.83 \pm 0.3^{* *}$ & 2.16 & 52.00 \\
\hline Standard (cimetidine $100 \mathrm{mg} / \mathrm{kg}+$ intoxication) & $0.5 \pm 0.22^{* * *}$ & 1.5 & 66.66 \\
\hline
\end{tabular}

The values are expressed as mean \pm SEM of six animals in each group and the results are analyzed using one way ANOVA. The values of treated groups are compared with those of intoxicated group. P-values are considered as significant $\left(^{*}\right)$ if $p<0.05$, more significant $\left(^{* *}\right)$ if $\mathrm{p}<0.01$ and highly significant $\left.{ }^{* * *}\right)$ if $\mathrm{p}<0.001$.

The effects of Pp.Cr on severity index of duodenal ulcer are tabulated in Table 2 . The mean value of severity score in intoxicated group, treated with cysteamine, was calculated as $2.5 \pm 0.22$. Cimetidine $(100 \mathrm{mg} / \mathrm{kg})$, an antisecretory agent, selected as the standard drug for the study, showed highly significant $(\mathrm{p}<0.001)$ reduction in severity score when compared with intoxicated group. The effects of Pp.Cr $(100 \mathrm{mg} / \mathrm{kg})$ on severity score were insignificant $(\mathrm{P}>0.05)$ when compared with intoxicated group. Pp.Cr (300 mg/kg) was able to reduce severity score significantly $(\mathrm{p}<0.05)$ as compared with intoxicated group. Pp.Cr $(500 \mathrm{mg} / \mathrm{kg})$ showed more significant $(\mathrm{p}<0.01)$ reduction in severity score as shown in Figure 3A.

\section{Effects of Pp.Cr on ulcer index}

Cysteamine produced the inflammatory changes and hemorrhagic spots in duodenum. No duodenal mucosal damage was observed in normal control group. The crude extract of Prunus persica (Pp.Cr) decreased the ulcer index in dose-dependent fashion as elaborated in Table 2. The value of ulcer index in intoxicated group was calculated as 4.5 ; whereas it was 1.5 in cimetidine treated group. The effects of Pp.Cr on ulcer indices in rats were found to be; $3.83,2.99$ and 2.16 at the doses of 100,300 and $500 \mathrm{mg} / \mathrm{kg}$ respectively. The effects of Pp.Cr $(500 \mathrm{mg} / \mathrm{kg})$ on ulcer index were comparable with cimetidine treated group as depicted in Figure 3B.

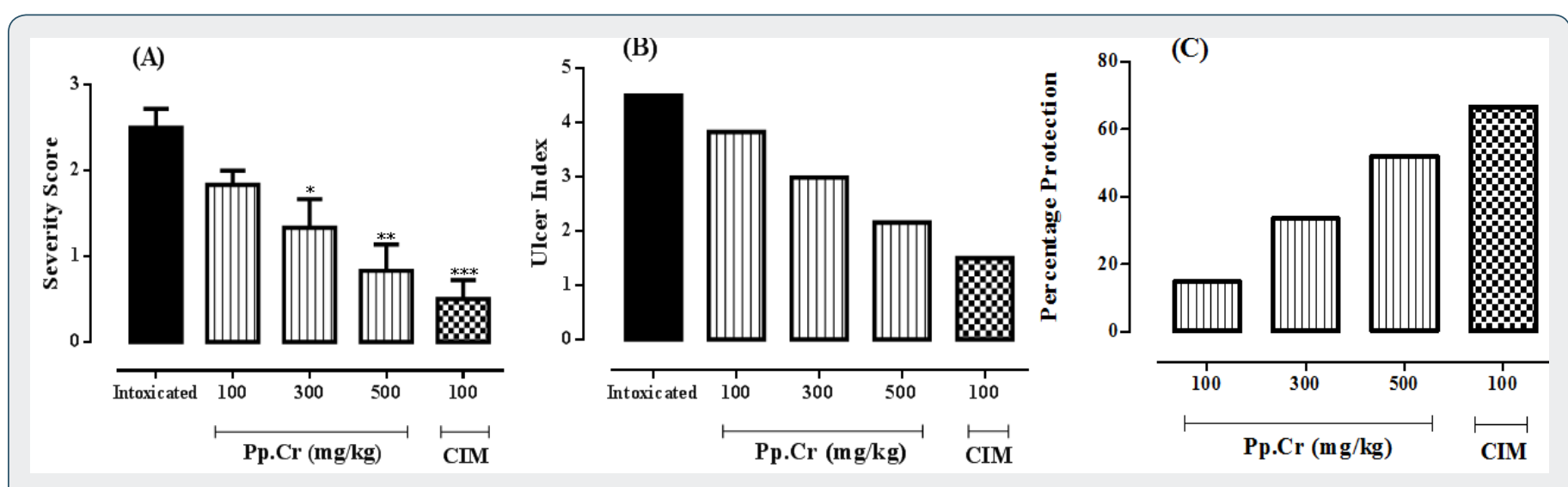

Figure 3: The graphs showing the effects of the crude extract Prunus persica (Pp.Cr) along with cimetidine (CIM), on (A) severity score, (B) Ulcer index and (C) percent protection in cysteamine-induced duodenal ulceration in rats. 


\section{Effects of Pp.Cr on Duodenal Percent Protection}

Oral administration of Pp.Cr showed the protection against cysteamine-induced duodenal ulcer. The percentage protection observed at the dose of $100 \mathrm{mg} / \mathrm{kg}$ was $14.88 \%$. The percentage protection was calculated as $33.55 \%$ at the dose of $300 \mathrm{mg} / \mathrm{kg}$. Similarly, at the dose of $500 \mathrm{mg} / \mathrm{kg}$ percentage protection was found to be $52 \%$ as depicted in Figure 3C. The standard drug cimetidine showed significant antiulcer effects with percentage protection of $66.66 \%$ (Table 2). The antiulcerogenic potential of Pp.Cr at the dose of $500 \mathrm{mg} / \mathrm{kg}$ was comparable with that of standard control group.

\section{Effects of Pp.Cr on Histopathological Parameters}

No mucosal damage was observed in normal control group (Figure 4A). Intoxicated group showed inflammation and hemorrhagic spots in duodenal mucosa (Figure 4B). Histological examination indicated that pretreatment with different doses $(100,300$ and $500 \mathrm{mg} / \mathrm{kg})$ of crude extract of Pp.Cr and cimetidine $(100 \mathrm{mg} / \mathrm{kg})$ showed the antiulcer effects as evidenced by reduction in inflammation and edema. Pretreatment with cimetidine showed the remarkable protection against cysteamine-induced duodenal ulcer (Figure 4F). Pp.Cr prevented the mucosal damage significantly (Figures 4C-4F).
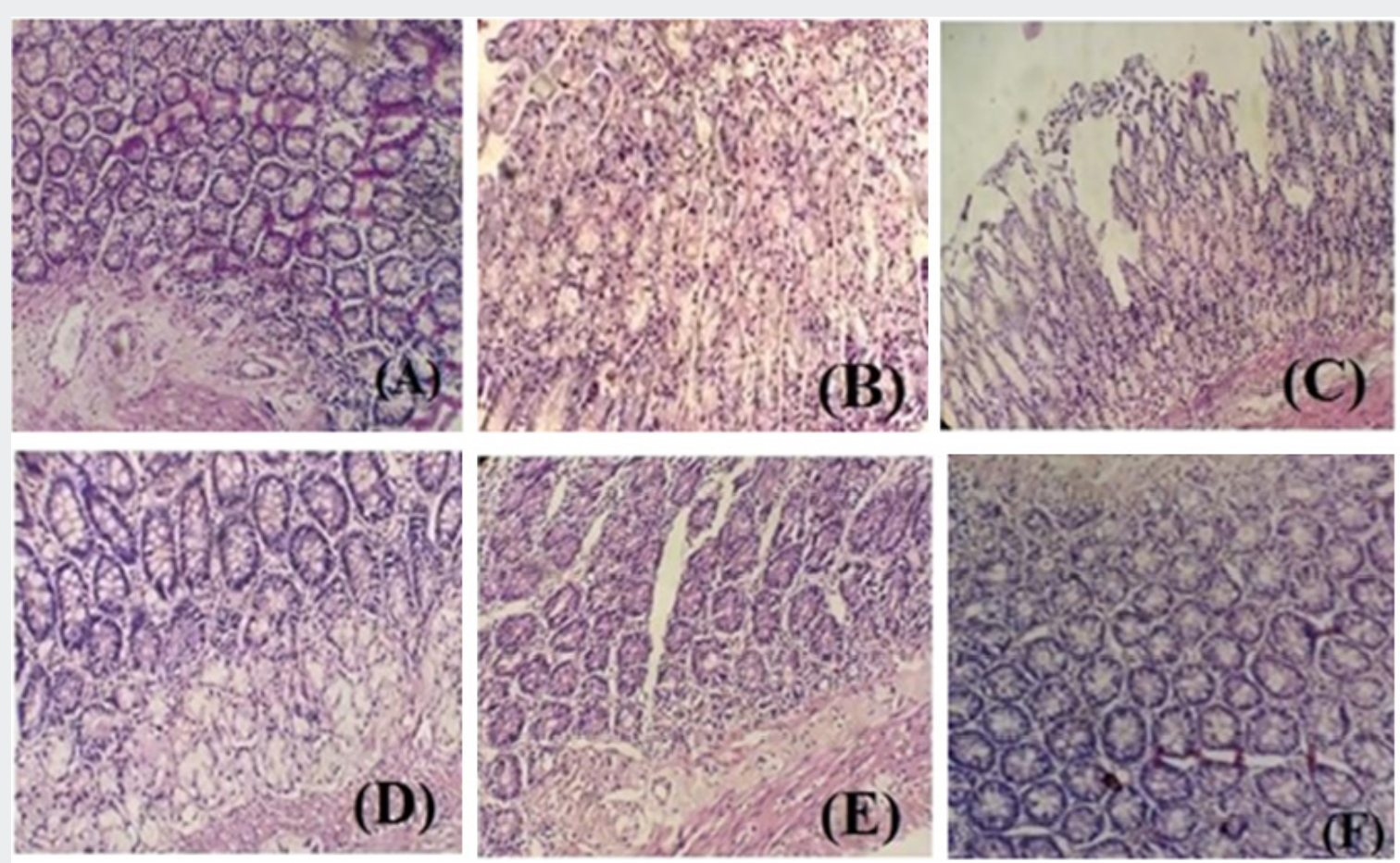

Figure 4: The effects of different doses of Pp.Cr and cimetidine on cysteamine-induced histopathogical alterations (A) normal control, (B) intoxicated (cysteamine hydrochloride $600 \mathrm{mg} / \mathrm{kg}$ ), (C) Pp.Cr $100 \mathrm{mg} / \mathrm{kg}+$ intoxication, (D) Pp.Cr 300mg/kg + intoxication, (E) Pp.Cr $500 \mathrm{mg} / \mathrm{kg}$ + intoxication and (F) CIM $100 \mathrm{mg} / \mathrm{kg}$ + intoxication.

\section{Discussion}

Ethanol has been reported to enhance the gastric acid secretion and reduce the blood flow, leading to microvascular injuries. It also causes the necrosis in the gastric mucosa, reducing the secretion of bicarbonates and gastric mucus [20]. Ethanol has also been found to induce mucosal cell surface damage and increases the permeability of mucosal capillaries, resulting in mucosal hemorrhage. These effects then allow the gastric acid back diffusion hence; exacerbate the mucosal damage already caused by ethanol [21]. So any substance that decreased the acid secretion or protects the mucosal layer could be gastroprotective. Standard drug, bismuth subsalicylate, showed the gastroprotective effects by forming a protective coating over gastric mucosa especially ulcerated sites to protect it from hydrolytic action of acid and pepsin. It also exerted the cytoprotective action by stimulating the prostaglandin biosynthesis, mucus and bicarbonate secretion [22]. The crude extract of Prunus persica (Pp.Cr) showed the presence of alkaloids, phenols and flavonoids. Alkaloids have been reported to possess the antiulcerogenic activity because of their ability to reduce gastric acid secretion, increase the $\mathrm{pH}$ of gastric contents and protect the mucous membrane [23]. Phenols have been reported to possess protective and therapeutic potential for peptic ulcer by up-regulating tissue growth factors and prostaglandins, down-regulating anti-angiogenic factors, enhancing endothelial nitric oxide synthase-derived NO, suppressing oxidative mucosal damage, amplifying antioxidant performance, antacid, and antisecretory activity and increasing endogenous mucosal defensive agents [24]. Flavonoids have been found to prevent the formation of free radicals and reduce injuries caused by oxidative stress [25]. Furthermore, Pp.Cr showed the presence of tannins which have been reported to produce layer over gut lining by precipitating 
micro proteins at ulcerative site, thus inhibit GIT secretions and also provide protection to gastrointestinal mucosa from irritants [26]. Tannins have also been found to resist the action of proteolytic enzymes produced by Helicobacter pylori [27].

Phytochemical analysis of Pp.Cr showed the presence of glycosides which have been found to reduce the expression of TNF- $\alpha$ [28]. Hence, the antiulcerative could be attributed to these secondary metabolites. $H$. pylori infection of the antral mucosa stimulates the release of gastrin by inhibiting the secretion of somatostatin. Gastrin has ability to enhance maximal acid secretory capacity. The administration of the crude extract of Prunus persica (Pp.Cr) was found to increase the $\mathrm{pH}$ of gastric contents, indicating that the extract could act as antisecretory agent because gastric acid back diffusion was one of major factors involved in the pathogenesis of ethanol- induced gastric ulcers. However, another possible mechanism of action could be its cytoprotective action; i.e. enhancement of the protective elements of the gastric mucosa; e.g. mucus and bicarbonate secretions in the same way as of bismuth subsalicylate, the standard drug. Exposure of gastric mucosa to necrotizing agents (e.g. ethanol) reduces these mucus and bicarbonate secretions, making gastric mucosa more susceptible to damaging action of gastric acid and pepsin. Ethanol also causes an increase in intracellular level of calcium, resulting in stimulation of gastric secretions [29]. The tannins present in the Pp.Cr could be the reason behind the decreased mucosal damage. The crude extract of Pp.Cr could also exert gastroprotective effects through cytoprotective action as ethanol has been reported to exert its direct toxic effects on gastric mucosa by reducing the secretion of bicarbonate ions and mucus. Ethanol has also been found to cause the gastric mucosal damage by producing free radicals leading to increased lipid peroxidation [30]. The P. persica plant extract could also have antioxidant potential that prevented the mucosal damage.

As peptic ulcer encompasses both gastric and duodenal ulcer, antiulcerogenic potential of the crude extract (Pp.Cr) was also assessed against cysteamine-induced duodenal ulcer alongwith ethanol-induced gastric ulcer. The cysteaime-induced duodenal ulcer model is a widely used and reproducible model of peptic ulcer because location, histopathology and pathophysiology of this chemically-induced ulcer are same as that of duodenal ulcer in humans [30]. Cysteamine has been studied to increase the gastrin level and thus increase the gastric acid secretory output. Cysteamine has also been reported to reduce the bicarbonate secretion and alkaline mucus secretion from the duodenal Brunner's gland. Moreover, cysteamine-induced delayed gastric emptying causes the accumulation of gastric secretions in stomach. Due to the absence of peristaltic movement, these secretions do not mix with gastric contents. When these concentrated secretions enter the duodenum, where bicarbonate secretion is already reduced by cysteamine, they promote the ulcer formation [30]. The preventive effects of Pp.Cr in cysteaime-induced duodenal ulcer could be due to the presence of various secondary metabolites such as alkaloids, glycosides and tannins. The scavenging effects of flavonoids and phenols present in the Pp.Cr may also the reason of protective outcomes in duodenal ulcer. The histopathological studies of both stomach and duodenum further confirm the results.

\section{References}

1. Mohan H, Mohan S (2010) Text Book of Pathology. Jaypee Brothers Medical Publishers (P) LTD, India.

2. Gulia Y, Choudhary M (2011) Peptic ulcer disease: a review. Pharmacologyonline 3: 48-70.

3. Avinash K, Abha D, Ganesh NS (2012) Peptic ulcer: a review with emphasis on plants from Cucurbetaceae family with antiulcer potential. International Journal of Research in Ayurveda and Pharmacy 2(6): $1714-1716$

4. Mitra P, Ghosh T, Mitra PK (2013) Anti-peptic Ulcer Activity of TLC Separated Fractions of Root Extract of Astilbe rivularis in rats. European Journal of Biotechnology and Bioscience 1(1): 37-42.

5. Wariss HM, Mukhtar M, Anjum S, Bhatti GR, Pirzada SA, et al. (2013) Floristic composition of the plants of the cholistan desert, Pakistan. American Journal of Plant Sciences 4: 58-65.

6. Aziz S (2013) Biological activities of Prunus persica L. batch. Journal of Medicinal Plants Research 7(15): 947-951.

7. Shin TY, Park SB, Yoo JS, Kim IK, Lee HS, et al. (2010) Anti-allergic inflammatory activity of the fruit of Prunus persica: role of calcium and NF-kappaB. Food and Chemical Toxicology 48(10): 2797-2802.

8. Edrah S, Fouzyalafid AK (2015) Preliminary phytochemical screening and antibacterial activity of Pistacia atlantica and Prunus persica plants of Libyan origin. International Journal of Science and Research 4: 15521555.

9. Raturi R, Singh H, Bahuguna P, Sati SC, Badoni PP (2011) Antibacterial and antioxidant activity of methanolic extract of bark of Prunus persica. Journal of Applied and Natural Science 3(2): 312-314.

10. Han S, Park K, Chung W, Lee SK, Kim J, et al. (2010) Anti-photoaging effects of 2-methoxy-5-(2-methyl propyl) pyrazine isolated from peach (Prunus persica (L.) Batsch). Food Science and Biotechnology 19(6): 1667-1671.

11. Han W, Xu JD, Wei FX, Zheng YD, Ma JZ, et al. (2015) Prokinetic activity of Prunus persica (L.) batsch flowers extract and its possible mechanism of action in rats. Bio Med Research International pp. 1-10.

12. Rafatullah S, Tariq M, Al Yahya MA, Mossa JS, Ageel AM (1990) Evaluation of turmeric (Curcuma longa) for gastric and duodenal antiulcer activity in rats. Journal of Ethnopharmacology 29(1): 25-34.

13. Pradhan D, Biswasroy P, Singh G, Suri KA (2013) Anti-ulcerogenic activity of ethanolic extract of Cucumis sativus L against NSAID (Aspirin) induced Gastric Ulcer in wistar albino rats. International Journal of Herbal Medicine 1(3): 115-119.

14. Ahmed N, Khan MSA, Jais AMM, Mohtarrudin N, Ranjbar M, et al. (2013) Antiulcer activity of sandalwood (Santalum album L.) stem hydroalcoholic extract in three gastric-ulceration models of wistar rats. Latin American and Caribbean Bulletin of Medicinal and Aromatic Plants 12(1): 81-91.

15. Santos RC, Kushima H, Rodrigues CM, Sannomiya M, Rocha LRM, et al. (2012) Byrsonima intermedia A. Juss.: Gastric and duodenal anti-ulcer, antimicrobial and antidiarrheal effects in experimental rodent models. Journal of Ethnopharmacology 140(2): 203-212.

16. Gregory M, Divya B, Mary RA, Viji M MH, Kalaichelvan VK, et al. (2013) Anti-ulcer activity of Ficus religiosa leaf ethanolic extract. Asian Pacific Journal of Tropical Biomedicine 3(7): 554-556. 
17. Orsi PR, Bonamin F, Severi JA, Santos RC, Vilegas W, et al. (2012) Hymenaea stigonocarpa Mart. ex Hayne: A Brazilian medicinal plant with gastric and duodenal anti-ulcer and antidiarrheal effects in experimental rodent models. Journal of Ethnopharmacology 143(1): 81-90.

18. Abdulla MA, Al-Bayaty FH, Younis LT, Abu Hassan MI (2010) Anti-ulcer activity of Centella asiatica leaf extract against ethanol-induced gastric mucosal injury in rats. Journal of Medicinal Plants Research 4(13): 1253-1259.

19. Ardestani SK, Watson RR (1995) 3 Immunomodulation by Alcohol. Drugs of Abuse, and Immune Functions 10: 27.

20. Mcquaid K R (2012) Drugs Used in the Treatment of Gastrointestinal Disoreders. In: Frassetto D, Henriquez RD (Eds.), Basic and Clinical Pharmacology. (12 ${ }^{\text {th }}$ edn), The McGraw-Hill Companies, USA.

21. Falcao H, Leite JA, Barbosa Filho JM, De Athayde Filho PF, De Oliveira Chaves MC, et al. (2008) Gastric and duodenal antiulcer activity of alkaloids: a review. Molecules 13(12): 3198-3223.

22. Farzaei MH, Abdollahi M, Rahimi R (2015) Role of dietary polyphenols in the management of peptic ulcer. World journal of gastroenterology 21(21): 6499-6517.

23. La Casa C, Villegas I, Alarcon-De-La Lastra C, Motilva V, Calero MMJ (2000) Evidence for protective and antioxidant properties of rutin, a natural flavone, against ethanol-induced gastric lesions. Journal of Ethnopharmacology 71(1-2): 45-53.

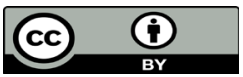

This work is licensed under Creative Commons Attribution 4.0 License

To Submit Your Article Click Here: Submit Article

DOI: $10.32474 /$ CTGH.2018.01.000107
24. Al-Rehaily AJ, Al-Howiriny TS, Al-Sohaibani MO, Rafatullah S (2002) Gastroprotective effects of 'Amla'Emblica officinalis on in-vivo test models in rats. Phytomedicine 9(6): 515-522.

25. Vasconcelos PCP, Kushima H, Andreo M, Hiruma Lima CA, Vilegas W, et al. (2008) Studies of gastric mucosa regeneration and safety promoted by Mouriri pusa treatment in acetic acid ulcer model. Journal of Ethnopharmacology 115: 293-301.

26. Chang H, Yang H, Lee T, Shin M, Lee M, et al. (2005) Armeniacae semen extract suppresses lipopolysaccharide-induced expressions of cycloosygenase- 2 and inducible nitric oxide synthase in mouse BV2 microglial cells. Biological and Pharmaceutical Bulletin 28(3): 449-454.

27. Dashputre NL, Naikwade NS (2011) Evaluation of anti-ulcer activity of methanolic extract of Abutilon indicum Linn leaves in experimental rats. International Journal of Pharmaceutical Sciences and Drug Research 3(2): 97-100.

28. Adinortey MB, Ansah C, Galyuon I, Nyarko A (2013) In vivo models used for evaluation of potential antigastroduodenal ulcer agents. Ulcers $p$. $1-12$.

29. Toma W, Trigo JR, Paula A, Brito AR (2004) Preventive activity of pyrrolizidine alkaloids from Senecio brasiliensis (Asteraceae) on gastric and duodenal induced ulcer on mice and rats. Journal of Ethnopharmacology 95(2-3): 345-351.

30. Morris PJ, Wood WC (2000) Oxford textbook of surgery. Oxford University Press UK.

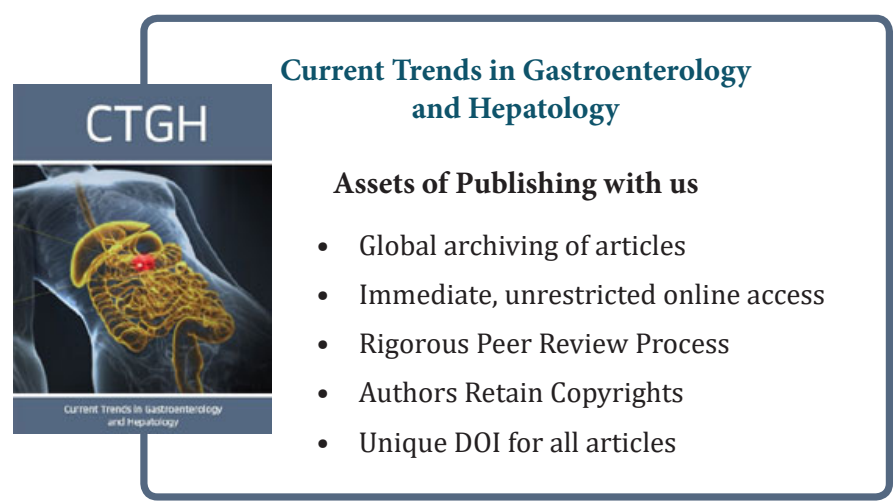

